\title{
A CASE OF DISSECTING ANEURYSM OF THE AORTA WLTH HEMIPLEGIA DIAGNOSED DURING LIFE
}

\author{
BY \\ MARGARET JAGO \\ From the Charing Cross Hospital Unit at Mount Vernon Hospital Middlesex
}

Shennan (1944) in his analysis of 300 cases of dissecting aneurysm of the aorta (up to and including 1932) reported only six correctly diagnosed before death. Among 153 cases reported by Reich (1944), and 12 by Logue, (1943), 36 and 10 respectively were correctly diagnosed. Reviewing these and some other reports, about 49 correct ante-mortem diagnoses have been made among 512 instances of the disease.

Differences in the carotid pulses were recorded by Nissim (1946) in one patient. The pulse was reduplicated on the right side and single on the left, without co-existing difference in the intensity of pulsation. He concluded that this was due to the difference in the rate of propogation of the pulse wave through the lumen of the artery and through its dissected coat, where the blood was probably partly clotted.

The following case is described because the diagnosis was finally made on the diminished pulsation of one carotid pulse. This was shown at necropsy to be due to pressure of the aortic aneurysm on the left carotid artery.

\section{Case Report}

A man, aged 62 , was admitted on $6 / 4 / 50$. Eight days previously he had a sudden attack of cramp-like pain in the centre of the chest, radiating into the back and down the left arm. The pain was very severe for the first 24 hours, and then steadily diminished until his admission to hospital, when he had a feeling of slight constriction only in the centre of the chest and in the small of the back. Four days after the onset of his symptoms he complained of recurring cramps in the calves.

In 1947, he had had a sudden attack of dizziness with amblyopia, lasting several days. He was told he had a high blood pressure. In 1948 his vision became blurred for a few days, but apart from these occurrences he had been well.

On examination he was of plethoric appearance with a temperature of $99^{\circ} \mathrm{F}$. The pulse rate was 90 per minute, with frequent extrasystoles; it was of high tension and equal on the two sides. The blood pressure was $270 / 160$ but no pulsus alternans was detected. The heart was enlarged with a thrusting apex beat in the fifth space, $11 \mathrm{~cm}$. from the mid-line. There was a generalized presystolic gallop rhythm with an apical systolic murmur; an aortic systolic murmur conducted into the neck was followed by a loud aortic second sound. The femoral and dorsalis pedis pulses were equal on palpation. Crepitations were heard at the bases of both lungs. No other abnormal physical signs were found.

On 11/4/50 an electrocardiogram showed a left ventricular preponderance, but no evidence of myocardial infarction. An X-ray of the chest showed a large left ventricle and an unfolding aorta with clear lung fields. On 13/4/50, a barium swallow was normal and there was no change in the cardiac or aortic shadows. The Wassermann reaction was negative and the blood urea $84 \mathrm{mg}$. per cent. The urine contained albumen, but no red cells or casts.

At this stage it was considered that this was probably a case of coronary thrombosis and he was treated with rest and sedatives only. 
His condition remained substantially the same until $18 / 4 / 50$, when he awoke in the night with a severe headache and was found to have a right hemiplegia affecting mainly the face and arm. He also had a nominal aphasia. The hemiplegia soon disappeared, although he still had a slight right facial weakness. That evening, however, the hemiplegia and aphasia recurred with weakness of the right side of the face, arm and leg; the right plantar response was extensor.

On 20/4/50 the blood pressure in the right arm was 240/160 and in the left 270/165. The femoral and dorsalis pedis pulses were present and equal, but the left cárotid pulse was found to be absent. Because of this and the repeated absence of the characteristic electrocardiographic changes of myocardial infarction, a diagnosis of dissecting aneurysm of the aorta was made. On 22/4/50 he had a severe attack of abdominal pain lasting several hours and he was incontinent of urine and

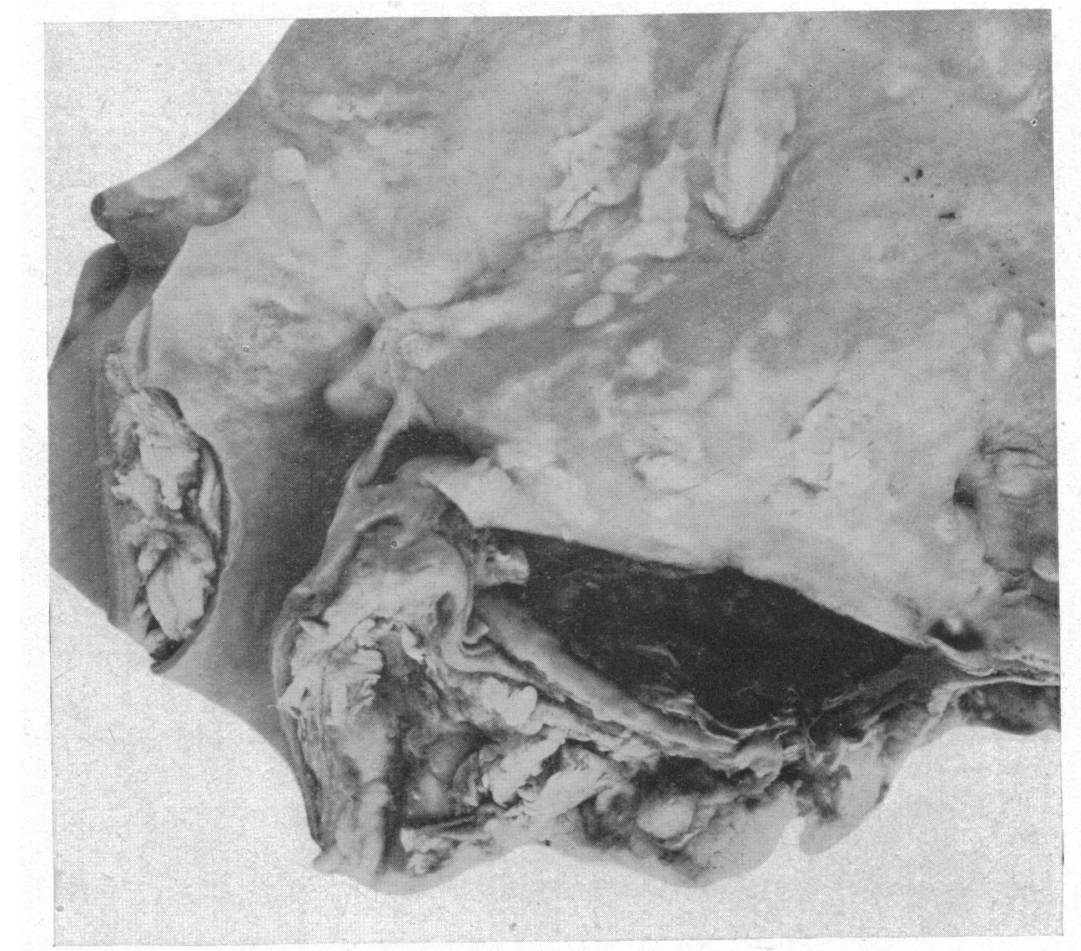

Fig. 1.-Aorta opened to show severe atheroma. At origin of left subclavian artery an intimal tear has given rise to a dissecting aneurysm which is opened to show soft red clots.

fæces. On 24/4/50 his condition was unchanged. Venesection was performed and he was given digitalis. He became comatose, with Cheyne-Stokes respiration on $27 / 4 / 50$, and on $28 / 4 / 50$ he died, 30 days after the onset of the original pain.

Necropsy. The heart was large with hypertrophy of the left ventricle. The other cavities and the valves were normal. The coronary arteries were dilated and tortuous with some atheroma, but good lumina. There was no evidence of thrombosis or infarction.

The whole aorta showed severe atheroma, the intima being covered with yellow and yellowishwhite patches. At the origin of the left subclavian, in relation to an atheromatous plaque, there was a small intimal tear from which a dissecting aneurysm had arisen (Fig. 1). This had spread along the left lateral aspect and, lower, down the posterior aspect of the aorta, reaching the external 
iliac arteries. It contained soft red clots. There was no evidence of true aortic stenosis. There was no occlusion of the carotid arteries by thrombosis or embolism.

Considerable arterial atheroma was seen in the brain, but there was no sign of recent infarction.

The lungs showed bilateral congestion with a little basal œedema and muco-pus in the basal bronchi.

A section of the thoracic aorta revealed that the aneurysm had split the media between the middle and outer third of its thickness. The space had become lined by intima-like tissue and there was hyaline change in the media and atheroma of the intima. There was no evidence of cystic medial necrosis (Fig. 2).

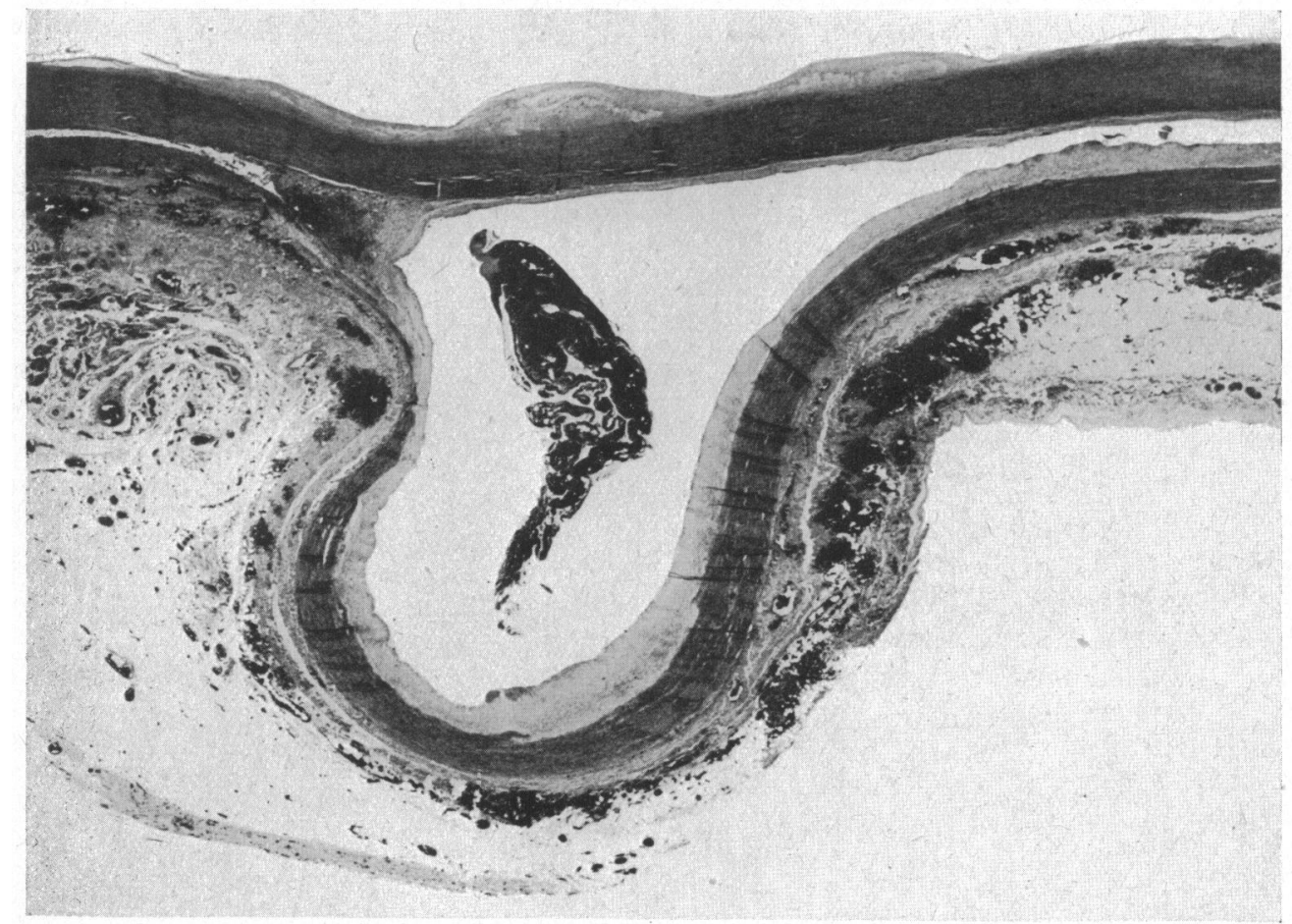

FiG. 2.-Section of dissecting aneurysm showing aneurysmal channel lined by intima. The medial tear and atheromatous plaques are seen. $(\times 8$.

\section{Discussion}

On looking back and comparing the clinical signs and symptoms with the necropsy findings, one perceives in this case a typical picture of dissecting aneurysm of the aorta. The pain in the chest was presumably directly due to dissection of the aorta, and the cramps in the calves to ischæmia of the femoral arteries. The history of dizziness and amblyopia can be accounted for by the hypertension and the abdominal pain by further dissection of the abdominal aorta. The right hemiplegia was secondary to the compression of the left carotid artery at its origin by the dissecting aneurysm.

Several significant signs of dissecting aneurysm of the aorta have been observed in recent years. Roesler et al. (1937) described the appearance of a rapidly shifting area of pulsation in the interscapular region, over which the second aortic sound was very accentuated. Another sign described by Logue (1943) consisted of a bruit and thrill over the femoral artery. Diminution in pulsation of one carotid artery can be added to this list and may prove a simple sign in suspected cases. 


\section{Summary}

A case of dissecting aneurysm of the aorta is described in which pressure of the aneurysm on the left common carotid artery resulted in a diminution of the left carotid pulse and a right hemiplegia. This sign enabled the diagnosis to be made during life.

My thanks are due to Dr. C. P. Silver for diagnosing the case, to Dr. C. D. Garratt for his kind assistance and to Dr. Hickling for his permission to publish the case.

\section{REFERENCES}

Logue, R. B. (1943) Amer. J. med. Sci., 206, 54.

Nissim, J. A. (1946). Brit. Heart J., 8, 203.

Reich, N. E. (1944). Clinics, 3, 346.

Roesler, H., Gifford, H. G., and Betts, W. (1937). Amer. Heat J., 13, 426.

Shennan, T. (1944). Dissecting Aneurysms. Spec. Rep. Ser., Med. Res. Council, London. 